Article

\title{
Sustainable Management of Organic Waste and Recycling for Bioplastics: A LCA Approach for the Italian Case Study
}

\author{
Giuliana Vinci ${ }^{1, *(\mathbb{D}}$, Roberto Ruggieri ${ }^{1}$, Andrea Billi ${ }^{2}$, Carmine Pagnozzi ${ }^{3}$, Maria Vittoria Di Loreto ${ }^{1}$ \\ and Marco Ruggeri ${ }^{1}$ (D)
}

1 Department of Management, Sapienza, University of Rome, Via del Castro Laurenziano 9, 00161 Rome, Italy; roberto.ruggieri@uniroma1.it (R.R.); mariavittoria.diloreto@gmail.com (M.V.D.L.); m.ruggeri@uniroma1.it (M.R.)

2 Department of Legal and Economic Studies, Sapienza, University of Rome, Piazzale Aldo Moro 5, 00185 Rome, Italy; andrea.billi@uniroma1.it

3 Assobioplastiche, Piazza di S. Bernardo, 109, 00187 Rome, Italy; direttore@assobioplastiche.org

* Correspondence: giuliana.vinci@uniroma1.it

Citation: Vinci, G.; Ruggieri, R.; Billi, A.; Pagnozzi, C.; Di Loreto, M.V.;

Ruggeri, M. Sustainable Management of Organic Waste and Recycling for Bioplastics: A LCA Approach for the Italian Case Study. Sustainability 2021, 13, 6385. https://doi.org/10.3390/ su13116385

Academic Editor: Farooq Sher

Received: 9 April 2021

Accepted: 2 June 2021

Published: 4 June 2021

Publisher's Note: MDPI stays neutral with regard to jurisdictional claims in published maps and institutional affiliations.

Copyright: (c) 2021 by the authors. Licensee MDPI, Basel, Switzerland. This article is an open access article distributed under the terms and conditions of the Creative Commons Attribution (CC BY) license (https:// creativecommons.org/licenses/by/ $4.0 /)$.
Abstract: The collection of the organic fraction in Italy recorded significant growth in the decade 2010-2019 (+74\%) due to both the increase in the spread of separate waste collection as well as the increase in the biological treatment plants of municipal waste. However, within the organic fraction there remains a share of non-compostable material (NCM) (plastic, glass, aluminum, etc.), equal to $\sim 5 \%$ of the total, which affects the efficiency of composting practices as well as decreasing both the yield and the quality of the final compost, causing a portion of organic material to be subtracted from composting and ending up in landfills. Therefore, the purpose of this work is to evaluate how the sustainability of the organic fraction collection and the amount of compost obtained in the composting plants could improve, following the use of biodegradable and compostable bioplastic bags (shoppers), in replacement for conventional plastic ones. The Life Cycle Assessment (LCA) and Carbon Footprint (CF) methodology was used for the assessment, comparing two different scenarios based on data relating to the collection of the organic fraction in Italy in 2019. Scenario 1 relates to the composting of organic material that also contains plastics, bioplastics, and non-compostable materials, while in scenario 2 the share of plastic material in the first scenario has been entirely replaced by bioplastics. The results show that scenario 2 assumes the lowest values for 15 impact categories out of the 18 analyzed, and, among these, in three categories it assumes negative values: ozone formation-terrestrial ecosystems $\left(-1.64 \times 10^{-2} \mathrm{~kg} \mathrm{NO} \times \mathrm{eq}\right)$, ozone formation-human health $\left(-8.50 \times 10^{-3} \mathrm{~kg} \mathrm{NO}\right.$ eq), and fossil resource scarcity $\left(-4.91 \times 10^{2} \mathrm{~kg}\right.$ oil eq). Furthermore, scenario 2 has a negative carbon footprint $\left(-3.80 \mathrm{~kg} \mathrm{CO}_{2} \mathrm{eq}\right)$ compared to scenario $1\left(79.71 \mathrm{~kg} \mathrm{CO}_{2}\right.$ eq), and in general it is the most sustainable scenario as a direct consequence of the greater amount of compost obtained (307.4 kg vs. $269.2 \mathrm{~kg})$.

Keywords: bioplastics; composting; life cycle assessment; carbon footprint

\section{Introduction}

Since the 1950s, plastic has become a pillar of the modern economy, thanks to its properties such as mechanical strength, lightness and flexibility, durability, and low cost. For this reason, it is used in many applications (packaging, agriculture, construction, automotive industry, household appliances, etc.) so that its global production went from 1.5 million tons in 1950 to 360 million tons in 2019 [1]. The production of conventional plastics, however, has two disadvantages: (i) it starts from fossil fuels; (ii) if not properly managed, collection and disposal accumulate in the environment as non-biodegradable material, polluting ecosystems and affecting biodiversity. To date, plastic waste management is not flawless: globally, annually, between 5 and 13 million tons of plastic end up in the oceans, slowly degrading into microplastics and causing devastating damage to ecosystems and human 
health [2,3]. Ocean plastics account for $80-85 \%$ of marine waste [4], and, of this percentage, disposable plastic accounts for $50 \%$ of the total. At European level, $70 \%$ of plastic waste ends up in landfill or is incinerated [5]. In this context, European legislation provides some regulatory responses to the problem of plastic waste. In particular, the EU Directive 2015/720 [6], acknowledged in Italy with Law 123/2017 [7], requires member states to ensure that the annual level of use of plastic shopping bags does not exceed 90 bags per capita by 31 December 2019 and 40 plastic bags per capita by 31 December 2025. As a result, alternatives to fossil plastics have been found, with their replacement in favor of bioplastics. It is a family of biological based polymers, whose carbon (C) usually comes from biological resources such as biomass (cellulose, starch, lignin, etc.) [8]. If the plastic precursor is a biological source, it can be considered bioplastic based biological (biobased), which can be biodegradable or non-biodegradable. In fact, the term "bio" before plastic gave rise to the misleading idea that all bioplastics were $100 \%$ biodegradable (capable of being degraded into simpler substances by the activity of microorganisms) or compostable (capable of being recycled organically together with wet materials, and transformed into hummus). However, the term refers to its source of $C$, and not necessarily to its biodegradability or compostability. In this regard, Figure 1 shows the three types of bioplastics.
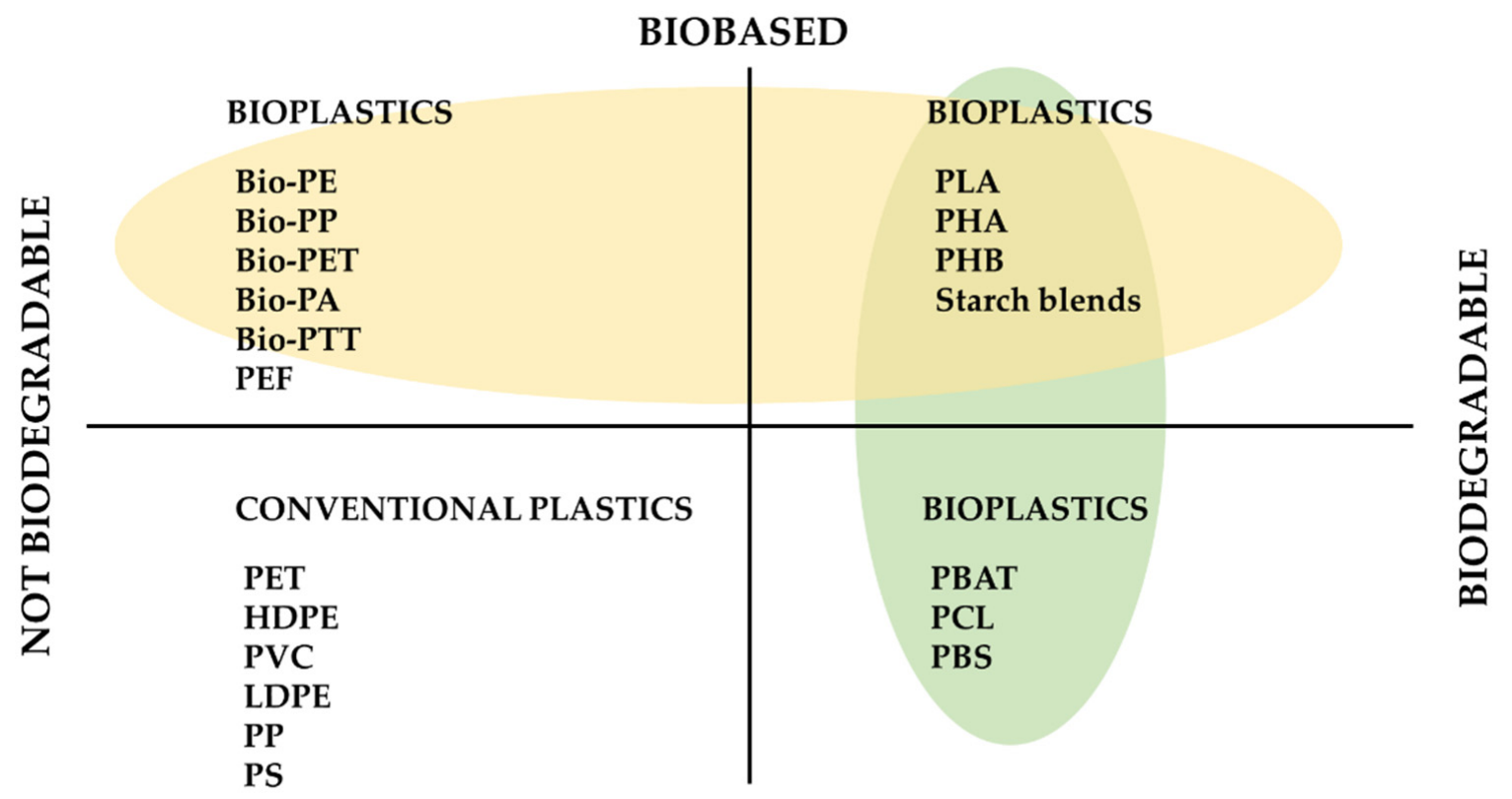

Figure 1. Types of plastics and bioplastics [1].

1. Polymers derived partly or entirely from renewable biomass (corn starch, sugar cane pulp, vegetable oil) which are non-biodegradable. They have the same chemical structure as fossil plastics, but the precursor is a biomass. Examples include biobased polyethylene (bio-PE), biobased polypropylene (bio-PP), biobased polyethylene terephthalate (bio-PET), bio polyamide (bio-PA), polytrimethylene terephthalate (bio-PTT), and polyethylene furanoate (bio-PEF).

2. Polymers derived partly or wholly from renewable biomass and based on EN 13432 are biodegradable and compostable, for example polylactic acid (PLA), polyhydroxyalkanoates (PHA), poly- $\beta$-hydroxybutyrate (PHB), and starch blends.

3. Polymers derived entirely from non-renewable raw materials which are biodegradable and compostable, for example polybutylene adipate terephthalate (PBAT), polycaprolactone (PCL), and polybutylene succinate (PBS). 
Bioplastics have some advantages over fossil plastics, such as reducing $\mathrm{CO}_{2}$ emissions [9], lower carbon footprint [10], and ability to be recycled among organic waste for compost production [11].

In addition, they are applied in various fields, including food packaging ( $52 \%$ of total production), but also textiles $(10 \%)$, consumer goods $(10 \%)$, automotive $(7 \%)$, agriculture $(7 \%)$, adhesives $(7 \%)$, construction $(4 \%)$, and other sectors (3\%) (Figure 2$)$ [12].

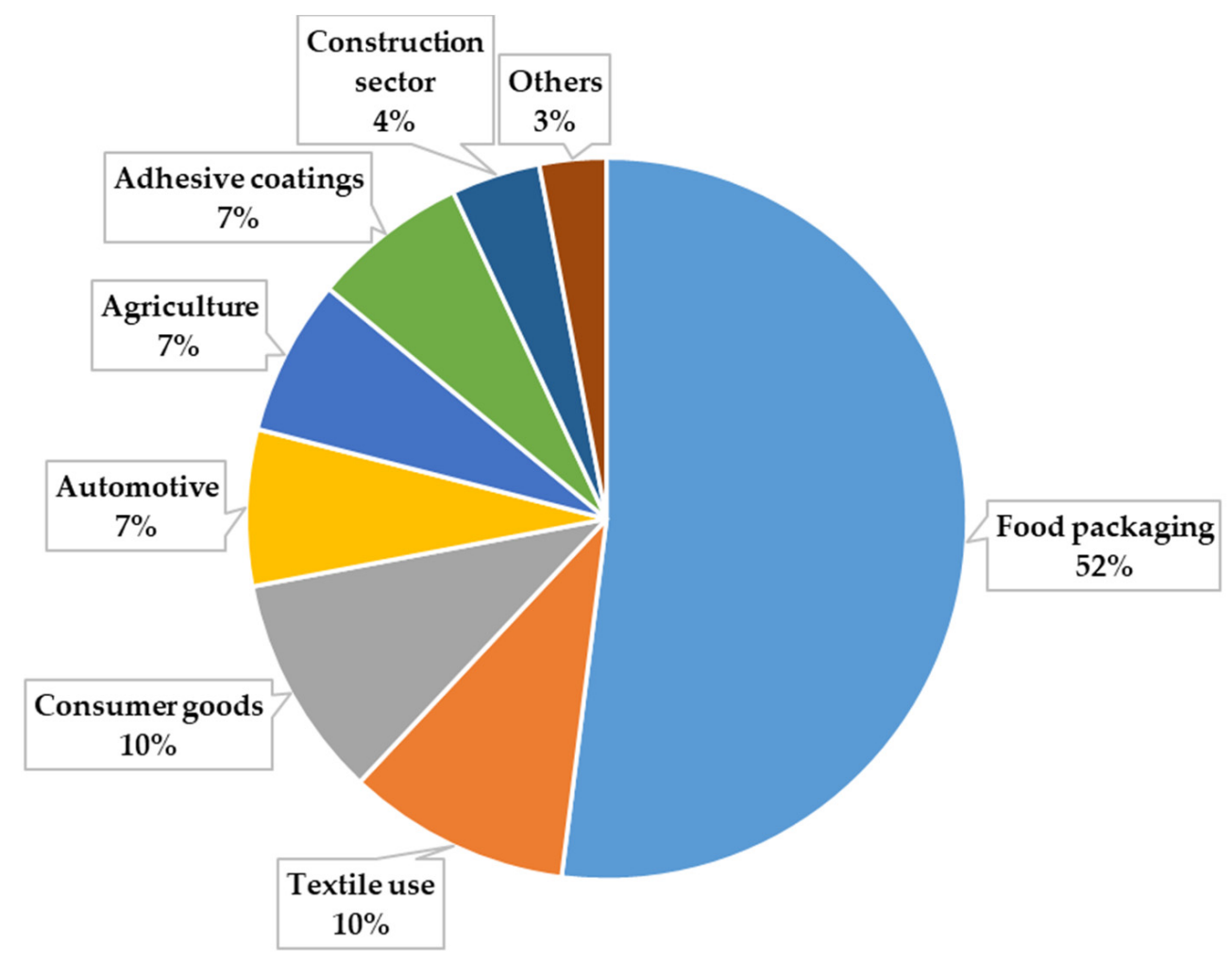

Figure 2. Main global uses of bioplastics [12].

However, bioplastics still represent a negligible percentage of total plastic production. In fact, in 2020 global bioplastic production was about 2.1 million tons (less than $1 \%$ of global plastic production) [1]. Their competitiveness is limited by several factors, including higher cost of production [13], which further hampers the replacement of fossil plastics by bioplastics. There are many challenges to be faced in the future, including lower production costs, similar mechanical properties to traditional ones, and adequate end-of-life management systems. In this regard, Italy is pioneering in terms of the management of biodegradable and compostable bioplastics, to the point that in 2021 the seventh branch of the "Consorzio Nazionale Imballaggi (CONAI)" was established (a private consortium that deals with the development of separate collection in Italy) [14], called "BioRepack" [15], the first created at the European level, which aims to ensure that bioplastics are properly managed in their disposal phase, separately from fossil plastics. Moreover, from 2012 to 2019 there has been an increment of the national production of bioplastics of $+157 \%$ passing from 39,000 tons (2012) to 101,000 tons (2019) (Figure 3A), with a consequent increase of the resolute employers that are almost doubled, from 1280 units in 2012 to 2645 in 2019 (Figure 3B), making it a sector capable of creating both value and employment [16]. The market segment that recorded the largest increase was that of ultralight, which includes both food packaging, both consumer products, including take-away bags, which in 2019 amounted to 54,000 tons (more than half of biodegradable and compostable bioplastics produced in Italy). The introduction of these biodegradable and compostable bags has meant that the collection of the organic and wet fraction, which in 2019 was equal to 7.3 million tons, increased by +1.3 million tons compared to 2015 [17]. The use of biodegradable and 
compostable bioplastics has contributed to this increase because their end-of-life follows the same processes as the organic fraction, being addressed either in composting plants or in integrated anaerobic-composting digestion. Therefore, the replacement of fossil-based plastics with biodegradable bioplastics is beneficial to the collection of organic materials, since returning to be compost, they become again the basis to produce the raw material from which the bioplastic itself is obtained, closing the cycle of the circular economy.

A

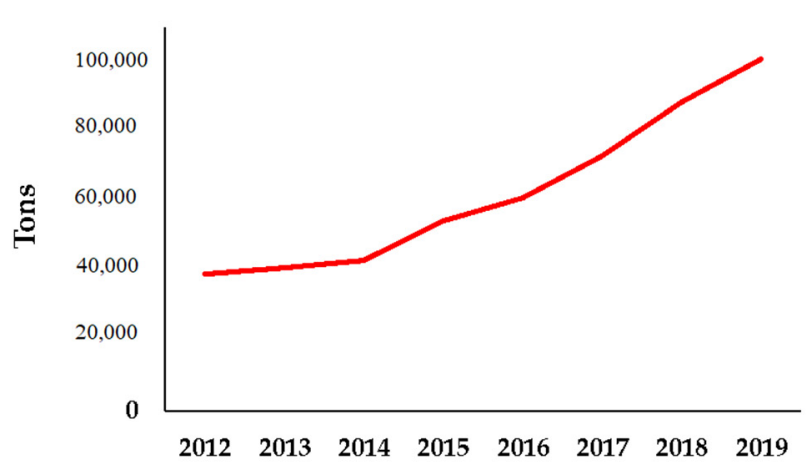

B

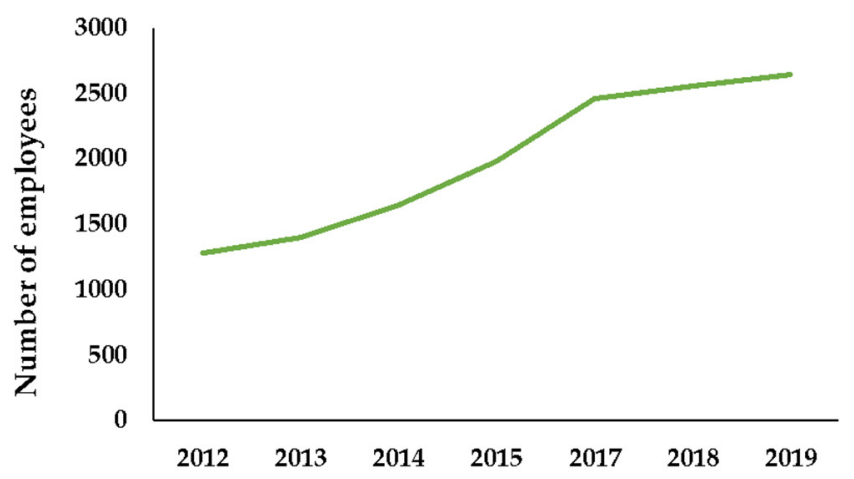

Figure 3. Evolution of production (A) and number of employers (B) in bioplastics in Italy. In Figure (B) data for 2016 are not available [16].

For some applications related to organic fraction management, bioplastics can offer alternatives to fossil-based plastic artefacts. It is critical to provide clear and comprehensive answers to the sustainability comparison between the two, whereas currently in Italy biodegradable and compostable bags amount to 54,000 $\mathrm{t}$ of 101,000 $\mathrm{t}$ of bioplastics produced. Therefore, the objective of this study was to assess how the sustainability of the collection of organic fractions and the amount of compost that is obtained in composting plants could improve because of the use of bags (shopper) in biodegradable and compostable bioplastics, replacing those in conventional plastic. Based on the data collected in Italy in 2019, two scenarios were therefore identified: scenario 1, or the composting of 1 ton of organic material, with plastics, bioplastics, non-compostable material, and organic waste. Scenario 2, which has the same inputs as scenario 1, involves plastics which have been replaced by the same proportion of bioplastics. To assess the impacts of both scenarios and, therefore, determine the most advantageous scenario, two tools were chosen: Life Cycle Assessment (LCA) and Carbon Footprint (CF). The first refers to two International Standard Organization (ISO), while the second refers to the guidelines of the International Panel on Climate Change which shows in $\mathrm{kg} \mathrm{CO}_{2}$ eq the total greenhouses gas emissions directly or indirectly associated with the service. SimaPro 8.5 software was chosen for the evaluation.

\section{Literature Background}

The bioplastics business has been established in the United States, Europe, and Japan since the early 1990s to address the problem of plastic waste in soil and marine ecosystems [18]. Given the biobased polymer nature of bioplastics, on Scopus the keywords "Polymers" and "Biopolymers" were used, and the relative percentage of articles is shown in Figure 4. It can be seen that since 2015 there has been an exponential growth in articles about this topic, underlining the remarkable interest of the research community. Currently the most common bioplastics are PLA, PBAT, bio-PA, bio-PE, and bio-PET (Table 1). Out of a total production of 2.1 million tonnes (2020) [1], the majority is produced in Asia (45\%), followed by Europe (25\%), North America (18\%), and finally South America (12\%) [1,12]. The global production of bioplastics also reflects the distribution of research articles. The articles are in fact distributed among about 90 countries, but among these mainly dominate Asian, European, and American Countries: USA (13\% of the total), Italy (6\%), Indonesia 
$(6 \%)$, Spain (6\%), India (6\%), Germany (5\%), Japan (5\%), and China (5\%). In general, the first bioplastic studies date back to the early 1990s and focus mainly on progress in the use of materials such as poly- $\beta$-hydroxybutyric acid (PHB) $[19,20]$, or thermoplastic starch [21], as promising candidates for the development of environmentally friendly and fully biodegradable plastics.

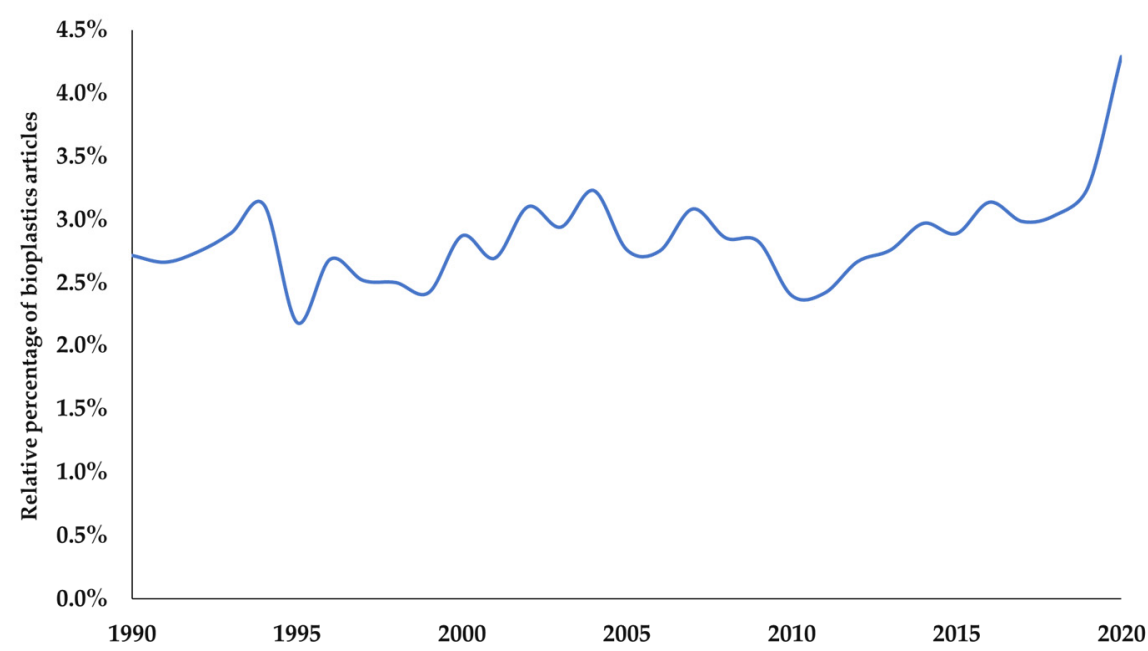

Figure 4. Scientific production regarding the topic "Biopolymers" (1990-2020, Scopus) as relative percentage of "Polymers".

Table 1. Global bioplastic market share, 2020 [1].

\begin{tabular}{|c|c|c|c|}
\hline \multirow{7}{*}{ Not biodegradable } & Biobased non biodegradable plastics & $40.8 \%$ & \multirow{7}{*}{$40.8 \%$} \\
\hline & bio-PE & $10.5 \%$ & \\
\hline & bio-PP & $1.4 \%$ & \\
\hline & bio-PET & $7.8 \%$ & \\
\hline & bio-PA & $11.9 \%$ & \\
\hline & bio-PTT & $9.2 \%$ & \\
\hline & bio-PEF & n.a. & \\
\hline \multirow{11}{*}{ Biodegradable } & Fossil based biodegradable plastics & $17.5 \%$ & \multirow{10}{*}{$59.2 \%$} \\
\hline & PBAT & $13.4 \%$ & \\
\hline & PCL & n.a. & \\
\hline & PBS & $4.1 \%$ & \\
\hline & Biobased biodegradable plastics & $41.7 \%$ & \\
\hline & PLA & $18.7 \%$ & \\
\hline & PHA & $1.7 \%$ & \\
\hline & PHB & n.a. & \\
\hline & Starch blends & $18.7 \%$ & \\
\hline & Others (PHB, PCL, bio-PEF, etc.) & $2.6 \%$ & \\
\hline & TOTAL & \multicolumn{2}{|c|}{$100 \%$} \\
\hline
\end{tabular}

Until the end of 2000, research on bioplastics was rather poor (50 articles), because it was still in its early stages and because technological advances in the plastics sector have led to greater reliability and cost-effectiveness compared to bioplastics, for which production processes were still inexpensive.

However, since the early 2000s, awareness of environmental issues related to plastics has led to research and development of new technologies to produce bioplastics. Therefore, bioplastic studies have increased accordingly.

At present, most bioplastic documents are in materials and environmental sciences (about $50 \%$ of the total) as well as chemical engineering, partly reflecting efforts to advance 
and improve existing technologies, trying to reconcile them with economic forerunners. For example, Krishnamurthy and Amritkumar (2019) [22] developed bioplastic films from jackfruit flour and sago as a cheap starch source, resulting in a product with good properties to be potentially applied in food packaging. Additionally, Arumugam et al. (2020) [23] used cashew apple juice (CAJ) as a carbon source to produce PHA to reduce its production costs. The results show good performance of the product obtained. In general, however, much bioplastic research is focused on the use of starchy-rich and renewable plant materials such as maize [24], potatoes [25], wheat [26], manioc, and vegetable oils [27,28]. However, the production of bioplastics from food precursors, in addition to the fact that it can often be costly, poses a further problem: obtaining bioplastics from food crops means taking away land and water from food production, which should be used for human consumption. In other words, the production of bioplastics from raw food materials could enter into direct competition with food production, potentially aggravating food insecurity in some poor areas, although this production represents a small percentage of land use and food production (about $0.015 \%-7$ million hectares_of all arable land worldwide) [1]. However, research has nevertheless focused on the production of bioplastics from other raw materials, not intended for food use such as microalgae $[29,30]$ or organic waste. For example, MooHuchin et al. (2020) [31] studied the use of huaya seed, considered as fruit waste as a precursor to produce bioplastics. The results of their study show that starch isolated from fruit seed flour can be a remarkably interesting alternative to the use of starches from unconventional sources, by application of food packaging. Bhatia et al. (2020) [32] reported recent progress in the production of PHA from various bio-waste such as municipal waste, dairy waste, slaughter waste, spent cooking oils, and waste from the biodiesel and oil industry. Since bioplastics were developed as potential substitutes for fossilbased plastics, an accurate comparison of their environmental and socio-economic impacts is essential to provide clear and comprehensive answers on comparative sustainability between bioplastics and fossil-based plastics. For this reason, many studies have focused on Life Cycle Assessment. One of the first LCA studies (from cradle to grave) was conducted by Razza et al. (2009) [33], which showed that significant environmental improvements can be achieved using non-biodegradable and non-compostable cutlery (polystyrene) and disposing of total waste by incineration and landfill (scenario 1) to an alternative scenario based on biodegradable and compostable (starch-based) cutlery with recovery of final organic and consequent composting (scenario 2). Based on their study, it emerges that with scenario 2 the consumption of non-renewable energy goes from 1490 to $128 \mathrm{MJ}$ generating an energy saving of +10 times greater and a saving of +3 times greater on greenhouse gases The same study was then repeated and expanded about ten years later, confirming that the use of biodegradable and compostable cutlery combined with organic recycling is the preferred option for catering, events, and fast food as it significantly reduces carbon, water, and resource footprint [34,35]. In 2011, however, Piemonte [36] analyzed what could be the best final disposal of bioplastic waste to maximize energy savings. Therefore, PLA and the starch-based bioplastic with PET and PE have been compared through LCA (from cradle to gate and from cradle to grave), demonstrating that in terms of global warming potential (100 years' time horizon) the PLA is less impactful than $-60 \%$ and $-35 \%$ compared to PET and PE, while the starch-based bioplastic leads to a reduction in GHG emissions of about $-45 \%$ and $-20 \%$ compared to PET and PE. Finally, Kim et al. (2020) [37] compared the environmental impacts of the production of 2.5-furandicarboxylic acid (FDCA), a bio-based material produced from biomass, with those of the production of terephthalic acid (TPA), produced from petroleum by LCA. In the case of the FDCA, its production results in a lower depletion of fossil resources than that of TPA production, although the carbon emissions of the former is greater $(+29 \%)$ than that of the latter. It follows that FDCA production can be sustainable by changing sources for electricity generation.

To date, LCA studies concerning bioplastics, and in particular the comparison between fossil plastics and bioplastic, are still limited. In fact, entering in Scopus the keywords "Bioplastics AND LCA" and "Bioplastics AND Plastics AND LCA" produced respectively 
65 documents and 52 documents, indicating that it is a research area still little explored. Therefore, an analysis of the end of life of bioplastics would allow us to highlight any environmental benefits and also to sensitize users to perform a proper collection of the organic fraction. Consequently, a comparison between the end-of-life of bioplastics and that of fossil-based plastics, both of which are used to collect the organic fraction, is worthy of interest in view of the effects they may have on the environment.

\section{Materials and Methods}

To conduct the analysis of the comparison between the use of biodegradable and compostable plastics and bioplastics for the collection of the organic fraction, the LCA methodology has been used, in accordance with the following standards:

- ISO 14040:2006_Environmental management_Life Cycle Assessment_Principles and framework

- ISO 14044:2006_Environmental management_Life Cycle Assessment—Requirements and guidelines.

The LCA is a valuable tool for comparing two or more options in terms of potential environmental, social, and economic impacts. It consists of four phases: (1) Goal and scope definition; (2) Life Cycle Inventory (LCI); (3) Life Cycle Impact Assessment (LCIA) 4) Interpretation. Simapro 8.5 software was used for the evaluation. The data used in this study were partly processed based on those collected by the "Istituto superior per la ricerca e la protezione ambientale (ISPRA)" (2019) [17] and from the monitoring program of "Consorzio Italiano Compostatori-Consorzio Recupero Plastiche (CIC - Corepla) 20192020" [38], partly based on previous studies [39]. The analyses conducted showed that 4.6 million tonnes of wet waste were collected in Italy in 2019. Of this quantity, the proportion of non-compostable material (plastic, aluminum, glass, diapers, coffee pods, etc.) was $5.2 \%$, of which $3.1 \%$ (145,000 tons/year) was fossil plastic. The number of compostable bioplastics amounted to $3.7 \%$ of the wet harvest (171,500 tons/year).

\subsection{Goal and Scope Definition}

The objective of this study was to assess the environmental impact of the use of biodegradable and compostable bioplastics compared to traditional plastics in the collection of the wet fraction. Two scenarios were considered for the comparison between plastic and bioplastic:

1. Scenario 1: Study of the current situation in Italy, where the organic fraction is composted together with both a share of bioplastics and a share of non-biodegradable plastics.

2. Scenario 2: Alternative scenario, where the share of fossil plastics is replaced with the same share of bioplastics and the organic fraction is composted together with them.

\subsubsection{Functional Unit}

The functional unit of this study is the treatment (composting) of 1 ton of wet fraction, consisting of:

1. Scenario 1: $911 \mathrm{~kg}$ of wet waste, $31 \mathrm{~kg}$ of plastic, $37 \mathrm{~kg}$ of compostable and biodegradable bioplastic (Polyester-complexed starch biopolymer), and $21 \mathrm{~kg}$ of noncompostable material.

2. Scenario 2: $911 \mathrm{~kg}$ of wet waste, $68 \mathrm{~kg}$ of compostable and biodegradable bioplastic (Polyester-complexed starch biopolymer), and $21 \mathrm{~kg}$ of non-compostable material.

Data on the two scenarios, taken from those present in the ISPRA database [17] and integrated with those of the monitoring program of Consorzio Italiano CompostatoriConsorzio Recupero Plastiche (CIC - Corepla) 2019-2020 [38] describe in a timely manner the number of fossil-based plastics and other non-compostable material present in the fraction of the wet collection in Italy. 


\subsubsection{System Boundaries}

The Life Cycle Assessment was conducted considering the treatment of organic waste in a composting plant (from gate to grave) (Figure 5), to assess the difference in terms of environmental impacts, between the use of biodegradable and compostable bags for wet harvesting (scenario 2) and the combined use of the latter with fossil-based plastic bags (scenario 1).

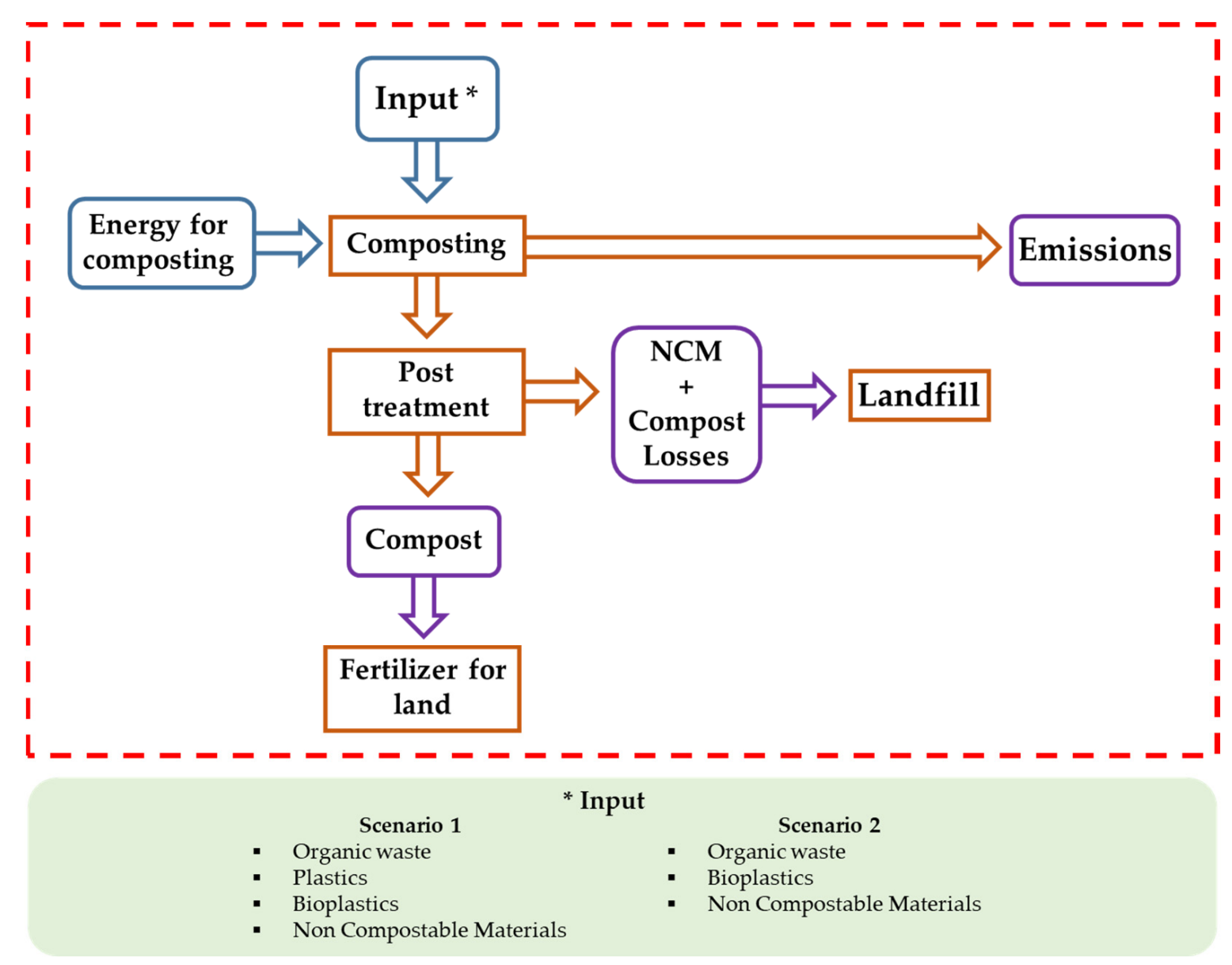

Figure 5. System boundaries (scenario 1 and scenario 2).

In the composting plant the humid fraction enters as an input, after which it undergoes aerobic digestion and, finally, through the post-treatment (screening), a certain amount of non-compostable material is eliminated (on average $5.2 \%$, including glass, etc.), obtaining the compost. This study did not consider both the transport of waste to treatment facilities and the production process of bioplastics and plastics, while both the application of compost to soil and the end-of-life landfill of non-compostable material (including fossilbased plastics) together with organic waste losses have been considered.

\subsection{Life Cycle Inventory (LCI)}

Table 2 shows the input and output data of scenario 1 and scenario 2.

Electricity consumption data were obtained from Al-Rumaihi et al. (2020) [39]. Regarding organic waste losses, both scenario 1 and scenario 2 considered the "dragging effect" exerted by the non-compostable material (including especially fossil plastics) within the organic fraction. This is a phenomenon whereby, during the screening process, parts of the organic fraction remain attached to the non-compostable material and end up in landfill/incinerator rather than in composting. This effect is estimated to result in a loss of $2.7 \mathrm{~kg}$ of organic fraction per $\mathrm{kg}$ of NCM [38]. Therefore, in scenario 1 there is an organic 
waste loss of $140.4 \mathrm{~kg}$, while in scenario 2 it amounts to $56.7 \mathrm{~kg}$ and this difference is because the proportion of plastics that was in scenario 1 was entirely replaced by bioplastics. It follows that the compostable material is higher in scenario $2(307.4 \mathrm{~kg})$ than scenario $1(269.2 \mathrm{~kg})$ (the final yield of the compost is about $1 / 3$ of the wet fraction) with an increase of $+14 \%$ due to the use of bioplastics.

Table 2. Life Cycle Inventory (LCI) of data for scenario 1 and scenario 2.

\begin{tabular}{cccc}
\hline Inputs/Outputs & Unit & Scenario 1 & Scenario 2 \\
\hline Inputs & & & \\
\hline Organic waste & $\mathrm{kg}$ & 911 & 911 \\
Bioplastics & $\mathrm{kg}$ & 37 & 68 \\
Plastics & $\mathrm{kg}$ & 31 & - \\
NCM & $\mathrm{kg}$ & 21 & 21 \\
Energy for & $\mathrm{kWh}$ & 9.52 & 9.52 \\
composting & $\mathrm{kWh}$ & 19.25 & 19.25 \\
Energy for air & & & \\
blowing & $\mathrm{kg}$ & 269.2 & 307.4 \\
Outputs & $\mathrm{kg}$ & 52 & 21 \\
\hline Compost & $\mathrm{kg}$ & 140.4 & 56.4 \\
NCM & & & -3.84 \\
Organic waste losses & $\mathrm{kg}$ & 76.8 & 10.1 \\
Emissions & $\mathrm{kg}$ & 17.6 & 0.00502 \\
CO $_{2}$ & $\mathrm{~g}$ & 1.2 &
\end{tabular}

\subsection{Life Cycle Impact Assessment (LCIA)}

The Life Cycle Impact Assessment phase provides information for the interpretation and comparison of the environmental performance of the two scenarios under consideration. The ReCiPe 2016 Midpoint (E) V1.01 method was used, which takes into account the following impact categories: global warming; stratospheric ozone depletion; ionizing radiation; ozone formation, human health; fine particulate matter formation; ozone formation, terrestrial ecosystems; terrestrial acidification; freshwater eutrophication; marine eutrophication; terrestrial ecotoxicity; freshwater ecotoxicity; marine ecotoxicity; human carcinogenic toxicity; human non-carcinogenic toxicity; land use; mineral resource scarcity; fossil resource scarcity; and water consumption. Then, in order to quantify the energy removed from nature by the two scenarios, the cumulative energy demand (CED) was calculated, a widely applied tool to study the energy used by a good or service during its life cycle. This is not intended to replace an assessment using comprehensive impact assessment methods, such as ReCiPe 2016 or ILCD 2011, but is meaningful as an integrated approach to confirm data from the analysis conducted using other methods.

\subsection{Carbon Footprint}

The carbon footprint (CF) of the scenarios under consideration was then calculated based on the LCI and LCIA. CF is a measure expressing the GHG emissions caused by a product, service, organization, event, etc. It is expressed in kilograms of $\mathrm{CO}_{2}$ equivalent ( $\mathrm{kg}$ of $\left.\mathrm{CO}_{2} \mathrm{eq}\right)$, and in agreement with the Kyoto protocol, the following gases are considered: carbon dioxide $\left(\mathrm{CO}_{2}\right)$, methane $\left(\mathrm{CH}_{4}\right)$, nitrous oxide $\left(\mathrm{N}_{2} \mathrm{O}\right)$, hydrocarbons, hydrofluorocarbons (HFCs), sulfur hexafluoride $\left(\mathrm{SF}_{6}\right)$, and perfluorocarbons (PFCs) [40]. Each GHG has a different greenhouse effect, so the CF has been calculated according to Forster et al. (2007) [41] as follows:

$$
\text { Carbon footprint }=\sum G \cdot G_{\cdot i} \times k_{i}
$$


where G.G.i is the amount of greenhouse gas produced and $k_{i}$ is the $\mathrm{CO}_{2}$ equivalent coefficient for that gas.

\section{Results and Discussion}

\subsection{ReCiPe 2016 Midpoint Method}

The application of the LCA has allowed the study and comparison between scenario 1 and scenario 2 described above, to assess the different environmental impact evaluation between the current Italian context and the scenario in which the amount of fossil plastics is completely replaced by biodegradable and compostable bags for the collection of the organic fraction. The method analyses 18 impact categories expressed in different units of measurement, whose results for the two different scenarios are shown in Table 3. The impact categories have been divided into three macro-areas: environmental (global warming; ozone formation, terrestrial ecosystems; terrestrial acidification; freshwater eutrophication; marine eutrophication; terrestrial ecotoxicity; freshwater ecotoxicity; marine ecotoxicity; land use; water consumption), social (stratospheric ozone depletion; ionizing radiation; ozone formation, human health; fine particulate matter formation; human carcinogenic toxicity; human non-carcinogenic toxicity), and economic (mineral resource scarcity; fossil resource scarcity). The negative values observed in the results reflect the environmental benefits of each impact category.

Table 3. Impact category values of the two scenarios.

\begin{tabular}{|c|c|c|c|}
\hline Impact Categories & Unit & Scenario 1 & Scenario 2 \\
\hline \multicolumn{4}{|c|}{ Environment } \\
\hline Global warming & $\mathrm{kg} \mathrm{CO}_{2} \mathrm{eq}$ & $1.76 \times 10^{2}$ & 57.0 \\
\hline $\begin{array}{l}\text { Ozone formation, Terrestrial } \\
\text { ecosystems }\end{array}$ & $\mathrm{kg} \mathrm{NO}_{x}$ eq & $2.22 \times 10^{-1}$ & $-1.64 \times 10^{-2}$ \\
\hline Terrestrial acidification & $\mathrm{kg} \mathrm{SO}_{2} \mathrm{eq}$ & 36.9 & 38.1 \\
\hline Freshwater eutrophication & $\mathrm{kg} P$ eq & $1.34 \times 10^{-2}$ & $2.06 \times 10^{-3}$ \\
\hline Marine eutrophication & $\mathrm{kg} \mathrm{N} \mathrm{eq}$ & $1.16 \times 10^{-3}$ & $1.79 \times 10^{-4}$ \\
\hline Terrestrial ecotoxicity & $\mathrm{kg} 1,4-\mathrm{DCB}$ & $1.01 \times 10^{2}$ & 27.9 \\
\hline Freshwater ecotoxicity & kg 1,4-DCB & 1.15 & $6.25 \times 10^{-1}$ \\
\hline Marine ecotoxicity & $\mathrm{kg} 1,4-\mathrm{DCB}$ & $8.98 \times 10^{3}$ & $2.63 \times 10^{3}$ \\
\hline Land use & $\mathrm{m} 2 \mathrm{a}$ crop eq & 2.59 & $6.0310^{-1}$ \\
\hline Water consumption & $\mathrm{m}^{3}$ & 1.42 & $7.96 \times 10^{-2}$ \\
\hline \multicolumn{4}{|c|}{ Social } \\
\hline Stratospheric ozone depletion & kg CFC11 eq & $2.58 \times 10^{-3}$ & $2.71 \times 10^{-3}$ \\
\hline Ionizing radiation & $\mathrm{kBq}$ Co-60 eq & 10.3 & 3.12 \\
\hline Ozone formation, Human health & $\mathrm{kg} \mathrm{NO}_{X} \mathrm{eq}$ & $2.11 \times 10^{-1}$ & $-8.50 \times 10^{-3}$ \\
\hline Fine particulate matter formation & $\mathrm{kg} \mathrm{PM}_{2.5} \mathrm{eq}$ & 4.61 & 4.68 \\
\hline Human carcinogenic toxicity & $\mathrm{kg} 1,4-\mathrm{DCB}$ & $2.23 \times 10^{2}$ & $1.53 \times 10^{-1}$ \\
\hline Human non-carcinogenic toxicity & kg 1,4-DCB & $7.19 \times 10^{3}$ & $2.07 \times 10^{3}$ \\
\hline \multicolumn{4}{|c|}{ Economic } \\
\hline Mineral resource scarcity & $\mathrm{kgCu}$ eq & $1.27 \times 10^{-1}$ & $2.95 \times 10^{-2}$ \\
\hline Fossil resource scarcity & kg oil eq & $-4.06 \times 10^{2}$ & $-4.91 \times 10^{2}$ \\
\hline
\end{tabular}

\subsubsection{Environment Impacts}

In 8 out of 10 categories, scenario 2 shows lower values than scenario 1 . In the case of global warming, it shows a significant reduction $\left(-67 \% \mathrm{~kg} \mathrm{CO}_{2} \mathrm{eq}\right)$ compared to scenario 1. Scenario 2 has negative values in respect to scenario 1 in the impact category "ozone formation, terrestrial ecosystems" $\left(-3.93 \times 10^{-2} \mathrm{~kg} \mathrm{NO}_{x}\right.$ eq). In general, a decrease in values can be observed in scenario 2 compared to scenario 1, except for the category 'terrestrial acidification' where the value is 3.3\% higher for scenario 2 than for scenario 1 . 


\subsubsection{Social Impacts}

Scenario 2 is more advantageous than scenario 1 for four out of six categories, with the exception of 'stratospheric ozone depletion' and 'fine particulate matter formation', where the values increase slightly in the ideal scenario compared to the real one, by $5 \%$ and $1.5 \%$, respectively.

\subsubsection{Economic Impacts}

Considering the impact categories related to the economic area (mineral resource scarcity and fossil resource scarcity), it is possible to calculate the cost savings due to the presence of only bioplastics instead of fossil plastics in scenario 2 [42]. Considering that 1 barrel of oil (158.99 L) costs approximately $€ 52.15$ (\$61.33) (April 2021), $1 \mathrm{~L}$ costs $€ 0.3280$. Therefore, since $1.2 \mathrm{~L}$ of oil $=1 \mathrm{~kg}$ of oil, the price of $1 \mathrm{~kg}$ of oil is $€ 0.3936$. Regarding copper $(\mathrm{Cu})$, its price is about $7.628 \times 10^{2} € /$ ton, so the price for $1 \mathrm{~kg}$ is $€ 7.626$.

From the results shown in Table 4, it emerges that Scenario 2 generates a total saving of $€ 33.89$ per ton of organic waste treated compared to Scenario 1 and is therefore the most financially sustainable scenario.

Table 4. Life Cycle Costing of the two scenarios.

\begin{tabular}{|c|c|c|c|c|c|c|}
\hline Impact Category & Scenario 1 & Scenario 2 & Price for $1 \mathrm{~kg}$ & $\begin{array}{c}\text { Cost of } \\
\text { Scenario } 1\end{array}$ & $\begin{array}{c}\text { Cost of } \\
\text { Scenario } 2\end{array}$ & Difference \\
\hline $\begin{array}{l}\text { Mineral resource } \\
\text { scarcity }\end{array}$ & $\begin{array}{c}1.27 \times 10^{-1} \mathrm{~kg} \\
\mathrm{Cu} \text { eq. }\end{array}$ & $\begin{array}{c}2.95 \times 10^{-2} \mathrm{~kg} \\
\mathrm{Cu} \text { eq. }\end{array}$ & $7.63 € / \mathrm{kg} \mathrm{Cu}$ & $0.9688 €$ & $0.23 €$ & $-0.74 €$ \\
\hline $\begin{array}{l}\text { Fossil resource } \\
\text { scarcity }\end{array}$ & $\begin{array}{c}-4.06 \times 10^{2} \mathrm{~kg} \\
\text { oil eq. }\end{array}$ & $\begin{array}{c}-4.91 \times 10^{2} \mathrm{~kg} \\
\text { oil eq. }\end{array}$ & $0.39 € / \mathrm{kg}$ oil & $-158.34 €$ & $-191.49 €$ & $-33.15 €$ \\
\hline Total & & & & $-157.37 €$ & $-191.26 €$ & $-33.89 €$ \\
\hline
\end{tabular}

Thus, on the total amount of organic waste collected in Italy in 2019 (4.6 million ton), the potential savings that could be made by applying scenario 2 is $153,894 €$.

The results were then characterized and expressed as a relative impact (Figure 6), where the scenario with the highest value in the impact category is set as the reference value $(100 \%)$ and the others percentual values are calculated consequently.

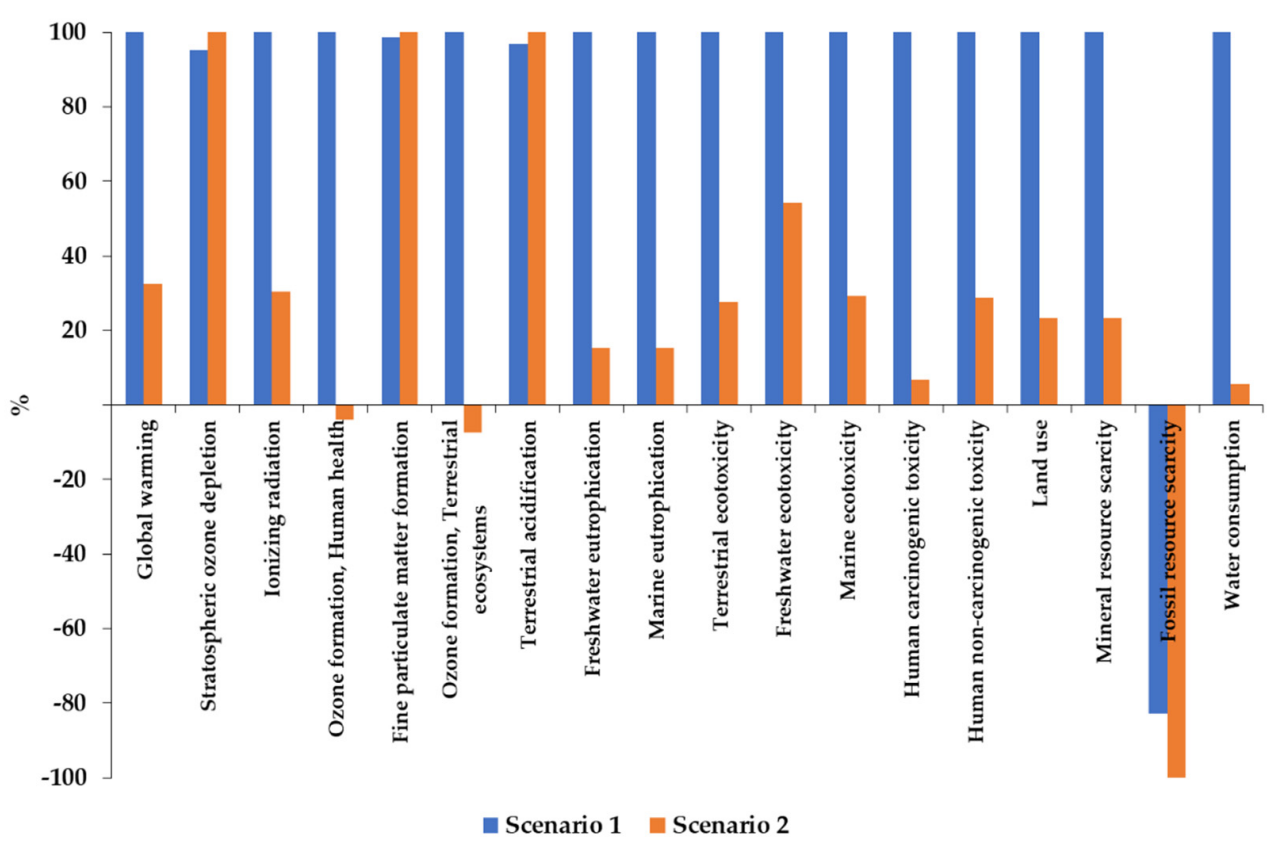

Figure 6. Results of the characterization of the impact categories of the two scenarios. 
For example, for the global warming category, the value of scenario 1 is $1.76 \times 10^{2} \mathrm{~kg}$ $\mathrm{CO}_{2}$ eq while for scenario 2 is $5.70 \times 10^{1} \mathrm{~kg} \mathrm{CO}$ eq. Through the characterization, the value of $1.76 \times 10^{2} \mathrm{~kg} \mathrm{CO}_{2}$ eq is set as $100 \%$, and the value of scenario 2 is calculated consequently and so set to $32.2 \%$. The result is a bar graph where on the $\mathrm{x}$-axis are the impact categories, and on the y-axis are the relative impacts in \%.

This type of visualization allows the Life Cycle Impact Assessment results to be more comprehensible, especially when using calculation methods, such as the ReCiPe 2016 Midpont, which considers 18 impact categories with different units of measurement. Hence, it is possible to analyze categories on the same scale and highlight specific trends in them. Through the characterization shown in Figure 6, it can be noted that scenario 2 has lower values in 15 out of 18 impact categories compared to scenario 1 , of which 3 categories have negative values (ozone formation, human health; ozone formation, terrestrial ecosystems; and fossil resource scarcity). This indicates how the use of biodegradable and compostable bags for the collection of the organic fraction allows an effective improvement of the analyzed environmental parameters compared to scenario 1 , especially for the impact categories global warming; ozone formation, human health and ozone formation, terrestrial ecosystems. The reduction in the global warming impact category is due to the decrease in organic waste losses, because of the substitution of the number of fossil-based plastics currently present in the organic waste collected in Italy, with biodegradable and compostable bioplastics. In scenario 2 , this substitution reduces organic waste losses due to the dragging effect and, consequently, increases the amount of final compost obtained, which can be considered a long-term carbon store. On the other hand, the reduction of values in scenario 2 compared to scenario 1 for the impact categories ozone formation, human health, and ozone formation, terrestrial ecosystems, is due to a decrease in $\mathrm{kg}$ of $\mathrm{NO}_{x}$ eq released into the environment.

$\mathrm{NO}_{\mathrm{X}}$, or nitrous oxide, is a group of molecules that once released into the atmosphere react photochemically with the volatile organic compounds (VOCs) causing the formation of tropospheric ozone $\left(\mathrm{O}_{3}\right)$. In this way the level of ground level ozone (GLO) increases and causes damage both to the environment and human health. For the category ozone formation, human health, $\mathrm{O}_{3}$ (a powerful oxidizing molecule) causes inflammation of the respiratory tract and lung tissues, with effects like increased incidence of lung cancer and asthma [43]. The unit of measurement of the ozone formation, human health category, is $\mathrm{NO}_{\mathrm{X}}$ eq chosen to simultaneously evaluate the impact of all the nitric oxide molecules that can be released into the atmosphere and refer them to a single unit of measurement. The benefits of compost are also noticeable for the fossil resource scarcity for both scenarios, as the use of compost allows for the recovery of nitrogen from organic waste, without the use of synthetic fertilizers, which require a lot of energy to be produced; from this perspective, compost provides a further reduction in global warming. Although scenario 2 is less impactful than scenario 1 in 15 out of 18 categories, it is nevertheless necessary to analyze these three categories where the ideal scenario appears to be more impactful for a complete and correct analysis of the obtained results. The stratospheric ozone depletion values in Table 3 show that, although there is a $5 \%$ increase between the two scenarios, the values obtained are $2.58 \times 10^{-3} \mathrm{~kg} \mathrm{CFC11} \mathrm{eq} \mathrm{for} \mathrm{scenario} 1$ and $2.71 \times 10^{-3} \mathrm{~kg}$ CFC11 eq for scenario 2 and are therefore negligible. Regarding fine particulate matter formation and terrestrial acidification, the values obtained are quite similar in the two scenarios with a slight increase in scenario 2 of $1.5 \%$ and $3.2 \%$ respectively, due to the composting process of organic waste. However, it must be considered that the $\mathrm{PM}_{2.5}$ and $\mathrm{SO}_{2}$ produced in the aerobic digestion phase, together with the other gases generated in this phase $\left(\mathrm{CO}_{2}, \mathrm{CH}_{4}\right.$, hydrocarbons), are not dispersed into the surrounding environment. In fact, the most advanced compost plants in Italy are biocells with a vacuum system, i.e., with the plant system characterized by an internal pressure lower than the external pressure. This technical aspect, together with the presence of suitable piping, means that the gases present, together with the water vapor, are conveyed to biofilters which have the function of retaining all the emissions from the aerobic composting phases. Therefore, 
in accordance with the previous description and for a correct interpretation of the results obtained, the data for the impact categories fine particulate matter formation and terrestrial acidification are to be considered negligible, as $\mathrm{PM}_{2.5}$ and $\mathrm{SO}_{2}$ are not actually released into the atmosphere.

\subsection{Cumulative Energy Demand (CED)}

The CED indicator has been divided into two main categories (renewable and nonrenewable) and eight sub-categories (fossil, nuclear, biomass, wind, solar, geothermal, and water). In this case, the values of the wind, solar, and geothermal subcategories have been aggregated. CED indicators are calculated based on the intrinsic value of energy, determined by the amount of energy subtracted from nature (expressed in MJequivalents). In detail, as shown in Table 5, scenario 2 leads to a reduction in the share of fossil resources $\left(-2.274 \times 10^{4} \mathrm{MJ}\right.$ eq vs. $-1.88 \times 10^{4} \mathrm{MJ}$ eq), due to the presence of more compostable material, determined by the presence of bioplastics, as well as a saving of resources derived from nuclear energy $\left(3.95 \times 10^{1} \mathrm{MJ}\right.$ eq vs. $3.58 \times 10^{2} \mathrm{MJ}$ eq $)$ and biomass renewable $\left(1.43 \times 10^{1} \mathrm{MJ}\right.$ eq vs. $5.40 \times 10^{1} \mathrm{MJ}$ eq $)$ and non-renewable $\left(5.95 \times 10^{-3} \mathrm{MJ}\right.$ eq vs. $3.23 \times 10^{-2} \mathrm{MJ}$ eq). The characterized results of the analysis (Figure 7 ) show a more sustainable situation for scenario 2 than for scenario 1 in all categories.

Table 5. Results (MJ eq) of Cumulative Energy Demand.

\begin{tabular}{ccc}
\hline Impact Categories & Scenario 1 & Scenario 2 \\
\hline Non-renewable, fossil & $-1.88 \times 10^{4} \mathrm{MJ} \mathrm{eq}$ & $-2.27 \times 10^{4} \mathrm{MJ} \mathrm{eq}$ \\
Non-renewable, nuclear & $3.58 \times 10^{2} \mathrm{MJ} \mathrm{eq}$ & $39.5 \mathrm{MJ} \mathrm{eq}$ \\
Non-renewable, biomass & $3.23 \times 10^{-2} \mathrm{MJ} \mathrm{eq}$ & $5.95 \times 10^{-3} \mathrm{MJ} \mathrm{eq}$ \\
Renewable, biomass & $54 \mathrm{MJ} \mathrm{eq}$ & $14.3 \mathrm{MJ} \mathrm{eq}$ \\
Renewable, wind, solar, geothermal & $13.4 \mathrm{MJ} \mathrm{eq}$ & $26.1 \mathrm{MJ}$ eq \\
Renewable, water & $70.3 \mathrm{MJ} \mathrm{eq}$ & $15.4 \mathrm{MJ}$ eq \\
\hline
\end{tabular}

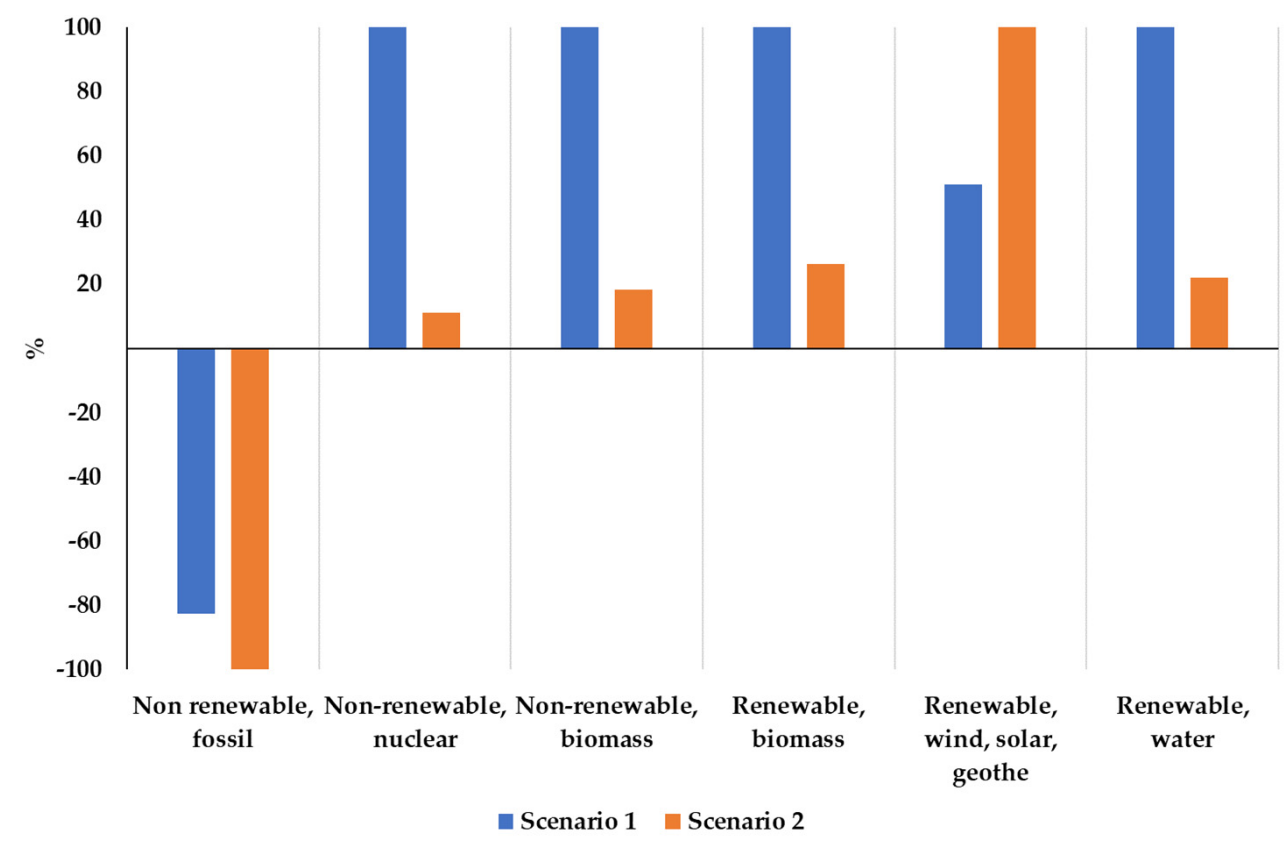

Figure 7. Cumulative energy demand of scenarios 1 and 2.

The presence of bioplastics leads to a significant increase in the use of renewable sources, as shown by the category "renewable, wind, solar, geothermal" that is higher for scenario 2, of which the largest share comes from wind energy (13.3 MJ eq), solar energy $\left(12.8 \mathrm{MJ}\right.$ eq), and finally geothermal energy $\left(1.39 \times 10^{-2} \mathrm{MJ}\right.$ eq) for a total of $26.1 \mathrm{MJ}$ eq. We 
refer to this transition from the use of fossil resources to renewable ones as "bioeconomy" which requires a systematic change of the entire energy and chemical industry. The main challenges of this economic model are energy security and climate change. In this context, the use of bioplastics can promote both the demand for energy from renewable sources and develop the economy towards a greater use of sustainable energies.

The results deriving from the Recipe method, which show that scenario 2 is more sustainable than scenario 1 , are corroborated by the CED.

\subsection{Carbon Footprint (CF)}

The carbon footprint is an objective assessment of the greenhouse gases (GHGs) generated by a product, process, or service, expressed in $\mathrm{kg}$ of $\mathrm{CO}_{2}$ eq. From the LCA results, it had been possible to highlight the air emissions of the two scenarios to have a list of all chemical species released. However, in accordance with the Kyoto Protocol, the following greenhouse gases were considered: $\mathrm{CO}_{2}, \mathrm{CH}_{4}, \mathrm{~N}_{2} \mathrm{O}$, hydrocarbons, $\mathrm{HFCs}, \mathrm{SF}_{6}$, and PFCs. The results are expressed in Figure 8.

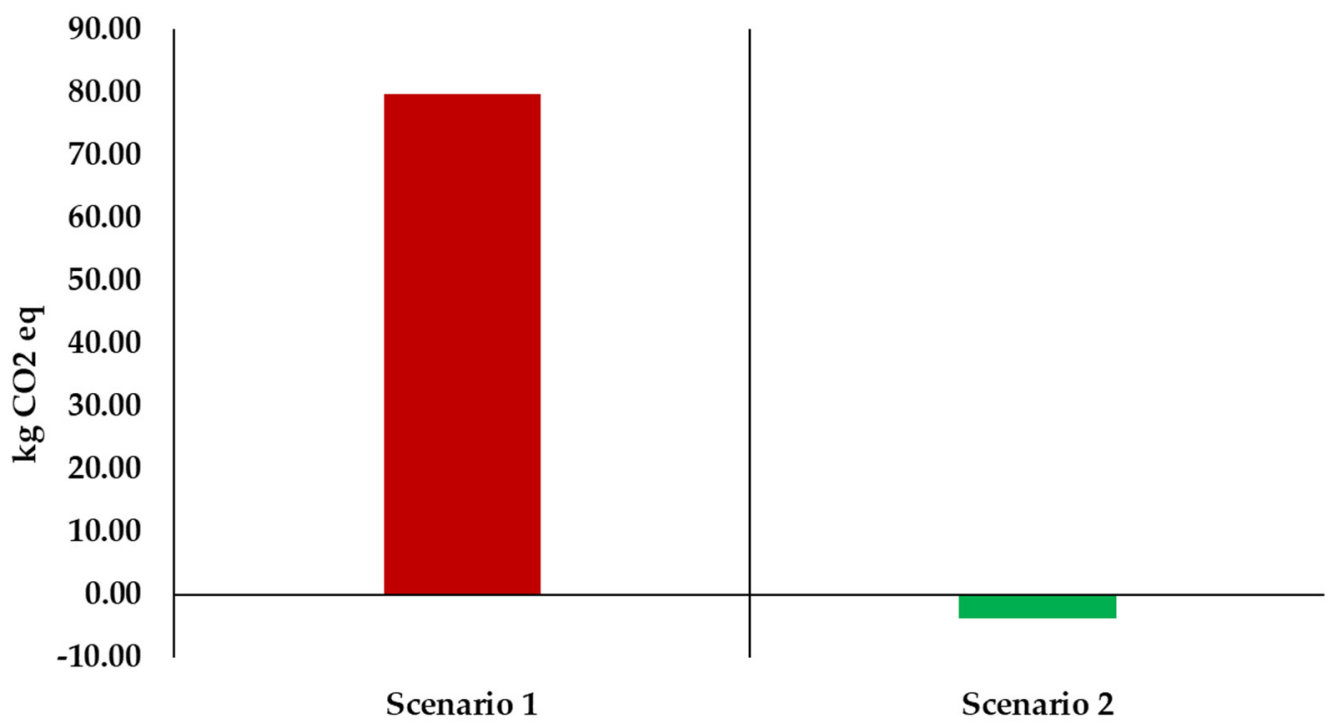

Figure 8. Carbon footprint of the two scenarios.

Interpretation of the results indicates that scenario 2 has a negative carbon footprint of $-3.80 \mathrm{~kg} \mathrm{CO} 2$ eq, while scenario 1 has a carbon footprint of $79.71 \mathrm{~kg}$ of $\mathrm{CO}_{2}$ eq. As already highlighted by the results of the LCA characterization phase, the advantage of the second scenario over the first could be because using biodegradable and compostable bags decreases the share of non-compostable material in the organic fraction, thus increasing the final compost yield. The latter decreases $\mathrm{CO}_{2}$ emissions because it acts as a long-term carbon sink as well as a fertilizer for fields, replacing chemical fertilizers. Indeed, this substitution would avoid the use of resources and energy to produce industrial fertilizers, and therefore, the substitution of nitrogen recovered from waste could potentially contribute to climate change mitigation. Therefore, the carbon footprint also confirms the LCA results.

\subsection{LCA from Cradle to Grave}

Our study considered only the end-of-life of bioplastics, through a "from gate to grave" analysis, from which it emerged that scenario 2, i.e., the one with only bioplastics, is more sustainable than scenario 1 where within the organic fraction there is also a certain amount of fossil plastics. Therefore, the whole life cycle has not been considered. However, it is necessary to ask a fundamental question in view of the results obtained: would scenario 2 represent a better solution even if the production of both fossil plastics and bioplastics was considered? In order to answer this question, a "from cradle to grave" analysis was conducted, with the aim of assessing the environmental impacts of the production processes 
and subsequent disposal of 1 tonne of bioplastic and 1 tonne of fossil plastic, of which the former is disposed of in composting plants and the latter in landfills. The results of this additional analysis are shown in Table 6.

Table 6. Results of LCA from cradle to grave.

\begin{tabular}{|c|c|c|c|}
\hline Impact Categories & Unit & Scenario 1 & Scenario 2 \\
\hline \multicolumn{4}{|c|}{ Environment } \\
\hline \multirow{2}{*}{$\begin{array}{l}\text { Global warming } \\
\text { Ozone formation, Terrestrial } \\
\text { ecosystems }\end{array}$} & $\mathrm{kg} \mathrm{CO}_{2} \mathrm{eq}$ & $2.53 \times 10^{3}$ & $1.29 \times 10^{3}$ \\
\hline & $\mathrm{kg} \mathrm{NO}_{\mathrm{x}} \mathrm{eq}$ & 7.02 & 4.12 \\
\hline Terrestrial acidification & $\mathrm{kg} \mathrm{SO}_{2} \mathrm{eq}$ & 9.32 & 19.0 \\
\hline Freshwater eutrophication & $\mathrm{kg} \mathrm{P} \mathrm{eq}$ & $3.37 \times 10^{-1}$ & $7.05 \times 10^{-1}$ \\
\hline Marine eutrophication & $\mathrm{kg} \mathrm{N} \mathrm{eq}$ & $2.86 \times 10^{-2}$ & 1.26 \\
\hline Terrestrial ecotoxicity & kg 1,4-DCB & $1.82 \times 10^{3}$ & $6.07 \times 10^{3}$ \\
\hline Freshwater ecotoxicity & kg 1,4-DCB & 21.9 & 64.2 \\
\hline Marine ecotoxicity & kg 1,4-DCB & $2.00 \times 10^{5}$ & $6.04 \times 10^{5}$ \\
\hline Land use & m2a crop eq & 73.5 & $7.26 \times 10^{2}$ \\
\hline Water consumption & $\mathrm{m}^{3}$ & 41.1 & 28.7 \\
\hline \multicolumn{4}{|c|}{ Social } \\
\hline Stratospheric ozone depletion & kg CFC11 eq & $4.97 \times 10^{-4}$ & $9.26 \times 10^{-3}$ \\
\hline Ionizing radiation & $\mathrm{kBq}$ Co-60 eq & $1.93 \times 10^{2}$ & $4.23 \times 10^{2}$ \\
\hline Ozone formation, Human health & $\mathrm{kg} \mathrm{NO}_{x}$ eq & 6.44 & 3.96 \\
\hline Fine particulate matter formation & $\mathrm{kg} \mathrm{PM}_{2.5} \mathrm{eq}$ & 3.53 & 4.20 \\
\hline \multirow{2}{*}{$\begin{array}{c}\text { Human carcinogenic toxicity } \\
\text { Human non-carcinogenic } \\
\text { toxicity }\end{array}$} & kg 1,4-DCB & $6.43 \times 10^{3}$ & $4.70 \times 10^{3}$ \\
\hline & kg 1,4-DCB & $1.59 \times 10^{5}$ & $4.99 \times 10^{5}$ \\
\hline \multicolumn{4}{|c|}{ Economic } \\
\hline Mineral resource scarcity & $\mathrm{kg} \mathrm{Cu} \mathrm{eq}$ & 1.97 & 5.84 \\
\hline Fossil resource scarcity & $\mathrm{kg}$ oil eq & $1.77 \times 10^{3}$ & 5.62 \\
\hline
\end{tabular}

If the entire production process is considered, scenario 2 is more impactful in 14 out of 18 categories than scenario 1 . However, observing the results expressed in Table 6, it can be seen that the stratospheric ozone depletion category can be considered negligible as its values are very low. Regarding the categories terrestrial acidification and fine particulate matter formation, it must be considered that the share of $\mathrm{SO}_{2}$ eq and $\mathrm{PM}_{2.5}$ eq generated during the composting process are not released into the atmosphere thanks to the presence of biofilters in the current composting plants in the Italian territory. The marine eutrophication category is higher for scenario $2(1.26 \mathrm{~kg} \mathrm{~N}$ eq) than for scenario $1\left(2.86 \times 10^{-2} \mathrm{~kg} \mathrm{~N}\right.$ eq $)$, due to the use of chemical fertilizers for the cultivation of raw materials. However, since the end-of-life of bioplastics is the production of compost, the latter can be used as a natural fertilizer in fields, decreasing the future need for chemical fertilizer use. Regarding the categories terrestrial ecotoxicity, freshwater ecotoxicity, marine ecotoxicity, human carcinogenic toxicity, and human non-carcinogenic toxicity, the values obtained are always higher for scenario 2, due to the use of pesticides in agriculture. Finally, with regard to the land use category, despite the fact that scenario 2 has superior values compared to scenario $1\left(7.26 \times 10^{2} \mathrm{~m}^{3}\right.$ crop eq vs. $7.35 \times 10^{1} \mathrm{~m}^{3}$ crop eq $)$, it must be considered that, in 2020, at global level, the land used for the cultivation of raw material for the production of bioplastics was equal to 0.7 million ha, $(0.015 \%$ of the entire world agricultural area). Therefore, the land allocated to the production of bioplastics is much lower than the share of land allocated to pasture (3.3 billion ha), food, and feed (1.24 billion ha) and that allocated to biofuels (53 million ha) [1].

Hence, although on the one hand the data obtained from the LCA should be contextualized and analyzed appropriately, on the other hand it emerges that the production processes of bioplastics are an innovation that allows for a link between industry and agri- 
culture and therefore its aspects should be explored in depth from both an environmental and economic point of view. Finally, in order to improve the production of bioplastics in this way, research is finding new opportunities in the development of bioconversion processes, i.e., the use of agro-food waste to obtain biopolymers and biomaterials with added value, making the production process feasible also on an industrial scale.

In fact, pushing the production of bioplastics from agro-food waste would reduce the use of virgin raw materials, while improving food waste management.

\section{Conclusions and Future Recommendations}

Using the Life Cycle Assessment and Carbon Footprint methodology, the study has assessed the environmental impacts and benefits of the two scenarios considered based on organic waste collection in Italy in 2019. The first scenario consists of composting 1 ton of organic material, which also contains plastic, bioplastic, and non-compostable material, while the second scenario sees the plastic portion replaced by the same portion of bioplastic. The Life Cycle Assessment was conducted using two methods: ReCiPe 2016 MidPoint and Cumulative Energy Demand. The first method considers eighteen categories of impact while the second considers energy removed from nature. The results show that scenario 2 is more sustainable in fifteen out of eighteen impact categories than scenario 1. Scenario 2 also presents negative values in three categories: ozone formation-terrestrial ecosystems $\left(-1.64 \times 10^{-2} \mathrm{~kg} \mathrm{NO}\right.$ eq), ozone formation-human health $\left(-8.5 \times 10^{-3} \mathrm{~kg} \mathrm{NO}\right.$ eq), and fossil resource scarcity $\left(-4.91 \times 10^{2} \mathrm{~kg}\right.$ oil eq). Conversely, it shows slightly higher values than in scenario 1 in the categories stratospheric ozone depletion $\left(2.58 \times 10^{-3} \mathrm{~kg}\right.$ CFC11 eq); fine particulate matter formation (4.68 $\left.\mathrm{kg} \mathrm{PM}_{2.5} \mathrm{eq}\right)$; and terrestrial acidification (38.1 $\mathrm{kg}$ $\mathrm{SO}_{2}$ eq). However, some considerations are necessary: the values of the stratospheric ozone depletion category can be considered negligible in the calculation of the environmental impact, while fine particulate matter formation and terrestrial acidification are causally related to the composting process, as they are generated by the aerobic digestion phase. Despite their production, these substances are not released into the atmosphere or the soil because the composting plants currently present in Italy are equipped with biofilters that serve to retain the emissions generated during the treatment of organic waste. Therefore, the values of these impact categories can be considered negligible. Using the Cumulative Energy Demand methodology, the results obtained with the ReCiPe method are confirmed as scenario 2 leads to a reduction in the amount of fossil resources, due to the presence of more compostable material by using bioplastics, as well as a greater increase in the consumption of renewable sources, thus contributing to reducing emissions and national energy dependence on fossil fuels. Finally, an objective assessment of the greenhouse gases (GHGs) generated by both scenarios, expressed in $\mathrm{kg}$ of $\mathrm{CO}_{2} \mathrm{eq}$, was conducted through the Carbon Footprint method, showing that scenario 2 generates a negative carbon footprint ( $-3.80 \mathrm{~kg}$ of $\mathrm{CO}_{2} \mathrm{eq}$ ) compared to scenario 1 (79.71 $\left.\mathrm{kg} \mathrm{CO}_{2} \mathrm{eq}\right)$. Hence, the second scenario is generally more sustainable than the first one, as the use of biodegradable and compostable bioplastic bags for the collection of the organic fraction contributes to improving waste management (reduction of the dragging effect), but above all closing the carbon cycle, regenerating the soil, and decarbonizing the atmosphere. The organic fraction often contains residues of non-compostable materials. These materials must be removed to avoid depreciation of the final product, the compost, compromising its final quality. This activity is expensive, not always effective and causes the loss of large amounts of compostable fractions. The use of bioplastics would reduce the percentage of NCM, leading to the recovery of a significant quantity of organic fraction that would otherwise be lost, and would also create a virtuous system, as expensive/inefficient systems for the selection of impurities would be avoided in the organic fraction treatment plants. As a result, a waste of resources due to landfilling could be avoided and at the same time the collection of humid waste could be increased, as the biodegradable and compostable bag naturally enters the collection of humid waste and follows the same disposal procedure (composting) avoiding screening process. 
Considering the analyses conducted and the results obtained, in future development of the research it is necessary to further investigate the issue of the correct disposal of the organic fraction in combination with bioplastics, both by expanding the economic effects (Life Cycle Costing) and by assessing the benefits also on a social level (Social Life Cycle Assessment) to analyze the three pillars of sustainability.

Italy, in fact, is the first Country in the European Union to develop the collection of the organic fraction and, consequently, complete and exhaustive studies in relation to this issue could lead, in the future, to the expansion and growth of the composting sector, which would have, as a direct consequence, an increase in jobs and rural development, as well as greater opportunities for the industries which manufacture biodegradable and compostable bioplastics.

Finally, to achieve continuous improvement and sustainable growth, it is also necessary to undertake and promote awareness campaigns on the practices to be adopted for the correct collection of the organic fraction to reduce the percentage of non-compostable material in it and, consequently, make composting more effective and efficient.

Author Contributions: All authors have contributed equally to the conceptualization and to the writing of the article. All authors have read and agreed to the published version of the manuscript.

Funding: This research received no external funding.

Institutional Review Board Statement: Not applicable.

Informed Consent Statement: Not applicable.

Data Availability Statement: Data generated is publicly available and cited in accordance with the journal's guidelines. All data used to support the results, as well as publicly archived data sets, analyzed or generated during the study were cited within the text.

Conflicts of Interest: The authors declare no conflict of interest.

\section{References}

1. Plastics Europe. Plastics—The Facts 2019. An Analysis of European Plastics Production, Demand and Waste Data. Available online: https:/ / www.plasticseurope.org/application/files/9715/7129/9584/FINAL_web_version_Plastics_the_facts2019_14 102019.pdf (accessed on 11 March 2021).

2. Geyer, R.; Jambeck, J.R.; Law, K.L. Production, use, and fate of all plastics ever made. Sci. Adv. 2017, 12, 66-68. [CrossRef] [PubMed]

3. Jambeck, J.R.; Geyer, R.; Wilcox, C.; Siegler, T.R.; Perryman, M.; Andrady, A.; Naraya, R.; Law, K.L. Plastic waste inputs from land into the ocean. Science 2015, 347, 768-771. [CrossRef] [PubMed]

4. Battista, F.; Frison, N.; Bolzonella, D. Can bioplastics be treated in conventional anaerobic digesters for food waste treatment? Environ. Technol. Innov. 2021, 22, 101393. [CrossRef]

5. European Parliamentary Research Service. Plastics in a Circular Economy: Opportunities and Challenges. Available online: https:/ / www.europarl.europa.eu/RegData/etudes/BRIE/2017/603940/EPRS_BRI(2017)603940_EN.pdf (accessed on 11 March 2021).

6. Directive (EU) 2015/720 of the European Parliament and of the Council of 29 April 2015 Amending Directive 94/62/EC as Regards the Reduction of the Use of Lightweight Plastic Bags. Available online: https:/ / eur-lex.europa.eu/legal-content/IT/ TXT/PDF/?uri=CELEX:32015L0720\&from=EN (accessed on 5 April 2021).

7. Legge 3 Agosto 2017, n. 123 (GU n.188 del 12 August 2017). Available online: https://www.gazzettaufficiale.it/eli/id/2017/08/ 12/17G00139/sg (accessed on 5 April 2021).

8. Rahman, M.D.H.; Bhoi, P.R. An overview of non-biodegradable bioplastics. J. Clean. Prod. 2021, 294, 126218. [CrossRef]

9. Pilla, S. Engineering Applications of Bioplastics and Biocomposites-An Overview. In Handbook of Bioplastics and Biocomposites Engineering Applications; Wiley-Scrivener: Beverly, MA, USA, 2011; pp. 1-15.

10. Bishop, G.; Styles, D.; Lens, P.N.L. Environmental performance comparison of bioplastics and petrochemical plastics: A review of life cycle assessment (LCA) methodological decisions. Resour. Conserv. Recycl. 2021, 168, 105451. [CrossRef]

11. Wojnowska-Baryła, I.; Kulikowska, D.; Bernat, K. Effect of Bio-Based Products on Waste Management. Sustainability 2020, 12, 2088. [CrossRef]

12. Brizga, J.; Hubacek, K.; Kuishuang, F. The Unintended Side Effects of Bioplastics: Carbon, Land, and Water Footprints. One Earth 2020, 3, 45-53. [CrossRef]

13. McKechnie, J.; Pourbafrani, M.; Saville, B.A.; MacLean, H.L. Environmental and financial implications of ethanol as a bioethylene feedstock versus as a transportation fuel. Environ. Res. Lett. 2015, 10, 124018. [CrossRef] 
14. Consorzio Nazionale Imballaggi (CONAI). Istituited with “D.lgs. 22/97", Subsequently Replaced by "D.lgs.152/06". Available online: https:/ / www.conai.org/ (accessed on 5 April 2021).

15. Consorzio Nazionale per il Riciclo Organico degli Imballaggi in Plastica Biodegradabile e Compostabile (Biorepack). Istituited with “Decreto 16 Ottobre 2020 del Ministero dell'ambiente e della Tutela del Territorio e del Mare". Available online: http: //www.biorepack.org/ (accessed on 5 April 2021).

16. $6^{\circ}$ Rapporto Plastic Consoult. Available online: https:/ / plasticconsult.it/ (accessed on 23 March 2021).

17. Istituto Superiore per la Protezione e la Ricerca Ambientale. Rapporto Rifiuti Urbani ed; (ISPRA, Rapporti 331/2020); 2020; ISBN 97888-448-1030-6. Available online: https:/ / www.isprambiente.gov.it/it/pubblicazioni/rapporti/rapporto-rifiuti-urbani-edizione2020 (accessed on 8 April 2021).

18. Kawashima, N.; Yagi, T.; Kojima, K. How Do Bioplastics and Fossil-Based Plastics Play in a Circular Economy? Macromol. Mater. Eng. 2019, 304, 1900383. [CrossRef]

19. Tamer, I.M.; Moo-Young, M.; Chisti, Y. Optimization of poly ( $\beta$-hydroxybutyric acid) recovery from Alcaligenes latus: Combined mechanical and chemical treatments. Bioprocess. Eng 1998, 19, 459-468. [CrossRef]

20. Bourque, D.; Ouellette, B.; André, G.; Groleau, D. Production of poly- $\beta$-hydroxybutyrate from methanol: Characterization of a new isolate of Methylobacterium extorquens. Appl. Microbiol. Biotechnol. 1992, 37, 7-12. [CrossRef]

21. Lörcks, J. Properties and applications of compostable starch-based plastic material. Polym. Degrad. Stab. 1998, 59, 245-249. [CrossRef]

22. Krishnamurthy, A.; Amritkumar, P. Synthesis and characterization of eco-friendly bioplastic from low-cost plant resources. SN Appl. Sci. 2019, 1, 1-13. [CrossRef]

23. Arumugam, A.; Anudakshaini, T.S.; Shruthi, R. Low-cost production of PHA using cashew apple (Anacardium occidentale L.) juice as potential substrate: Optimization and characterization. Biomass Conv. Bioref. 2020, 10, 1167-1178. [CrossRef]

24. Amalia, D. Synthesis of Biodegradable Plastics Using Corn Starch and Corn Husk as the Fillers as Well as Chitosan and Sorbitol. In Journal of Physics: Conference Series; IOP Publishing: Bristol, UK, 2020.

25. Shafqat, A.; Al-Zaqri, N.; Tahir, A.; Alsalme, A. Synthesis and characterization of starch based bioplatics using varying plant-based ingredients, plasticizers and natural fillers. Saudi J. Biol. Sci. 2021, 28, 1739-1749. [CrossRef]

26. Dominici, F.; Luzi, F.; Benincasa, P.; Torre, L.; Puglia, D. Biocomposites based on plasticized wheat flours: Effect of bran content on thermomechanical behavior. Polymers 2020, 12, 2248. [CrossRef]

27. Navia Porras, D.P.; Gordillo Suárez, M.; Hernández Umaña, J.; Poveda Perdomo, L.G. Optimization of Physical, Optical and Barrier Properties of Films Made from Cassava Starch and Rosemary Oil. J. Polym Environ. 2019, 27, 127-140. [CrossRef]

28. Syamani, F.A.; Pramasari, D.J.; Kusumaningrum, W.B.; Kusumah, S.S.; Masruchin, N.; Ermawati, R.; Supeni, G.; Cahyaningtyas, A.A. Characteristics of Bioplastic Made from Cassava Starch Filled with Fibers from Oil Palm Trunk at Various Amount. In IOP Conference Series: Earth and Environmental Science; IOP Publishing: Bristol, UK, 2020; Volume 439, p. 012035.

29. Devadas, V.V.; Khoo, K.S.; Chia, W.Y.; Chew, K.W.; Munawaroh, H.S.H.; Lam, M. Algae biopolymer towards sustainable circular economy. Bioresour. Technol. 2021, 325, 124702. [CrossRef]

30. Thiruchelvi, R.; Das, A.; Sikdar, E. Bioplastics as better alternative to petro plastic. Mater. Today Proc. 2020, 37 Pt 2, $1634-1639$. [CrossRef]

31. Moo-Huchin, V.M.; Ac-Chim, D.M.; Chim-Chi, Y.A.; Ríos-Soberanis, C.R.; Ramos, G.; Yee-Madeira, H.T. Huaya (Melicoccus bijugatus) seed flour as a new source of starch: Physicochemical, morphological, thermal and functional characterization. J. Food Meas. Charact. 2020, 14, 3299-3309. [CrossRef]

32. Bhatia, S.K.; Otari, S.V.; Jeon, J.; Gurav, R.; Choi, Y.; Bhatia, R.K.; Yang, Y. Biowaste-to-bioplastic (polyhydroxyalkanoates): Conversion technologies, strategies, challenges, and perspective. Bioresour. Technol. 2020, 326, 124733. [CrossRef] [PubMed]

33. Razza, F.; Fieschi, M.; Innocenti, F.D.; Bastioli, C. Compostable cutlery and waste management: An LCA approach. Waste Manag. 2009, 29, 1424-1433. [CrossRef]

34. Fieschi, M.; Pretato, U. Role of compostable tableware in food service and waste management. A life cycle assessment study. Waste Manag. 2018, 73, 14-25. [CrossRef]

35. Ita-Nagy, D.; Vázquez-Rowe, I.; Kahhat, R.; Chinga-Carrasco, G.; Quispe, I. Reviewing environmental life cycle impacts of biobased polymers: Current trends and methodological challenges. Int. J. Life Cycle Assess. 2020, 25, 2169-2189. [CrossRef]

36. Piemonte, V. Bioplastic wastes: The best final disposition for energy saving. J. Polym. Environ. 2011, 19, 988-994. [CrossRef]

37. Kim, H.; Lee, S.; Ahn, Y.; Lee, J.; Won, W. Sustainable Production of Bioplastics from Lignocellulosic Biomass: Technoeconomic Analysis and Life-Cycle Assessment. ACS Sustain. Chem. Eng. 2020, 8, 12419-12429. [CrossRef]

38. Programma di Monitoraggio CIC_COREPLA (2019-2020). Available online: https:/ / www.compost.it (accessed on 5 April 2021).

39. Al-Ruhmahi, A.; McKay, G.; Mackey, H.R.; Al-Ansari, T. Environmental impact assessment of Food Waste management using two composting techniques. Sustainability 2020, 12, 1595. [CrossRef]

40. IPPC. 2006 IPCC Guidelines for National Greenhouse Gas Inventories-Volume 3-Industrial Processes. Available online: https: / / www.ipcc-nggip.iges.or.jp/ (accessed on 23 March 2021).

41. Forster, P.; Artaxo, P. Changes in Atmospheric Constituents and in Radiative Forcing. In Climate Change 2007: The Physical Science Basis; Contribution of Working Group I to the Fourth Assessment Report of the Intergovernmental Panel on Climate Change; Solomon, S., Qin, D., Manning, M., Chen, Z., Marquis, M., Averyt, K.B., Tignor, M., Miller, H.L., Eds.; Cambridge University Press: Cambridge, UK; New York, NY, USA, 2007. 
42. Vinci, G.; Rapa, M. Hydroponic cultivation: Life cycle assessment of subrstrate choice. Br. Food J. 2019, 121, 8. [CrossRef]

43. Manisalidis, I.; Stavropoulou, E.; Stavropoulous, A.; Bezirtzoglou, E. Environmental and Health Impacts of Air Pollution: A review. Front. Public Health 2020, 8, 14. [CrossRef] [PubMed] 